\title{
Area-Based Management Tools, Including Marine Protected Areas-Reflections on the Status of Negotiations
}

\author{
Lisa Eurén Höglund
}

\begin{abstract}
The negotiations on Area-based management tools and Marine Protected Areas (MPAs) are well advanced. There are several points most positions have in common, such as consultations before a decision on a new MPA, and why the strict division between the "global approach" and the "regional approach" may be misleading.

This paper is based on a presentation that was presented shortly after the second substantive session of negotiations. States were anxiously waiting for the President of the conference, Ambassador Rena Lee, to publish the next document to guide the negotiations. The aim of the presentation was to illustrate the status of the negotiations on the topic "Area-based management tools, including marine protected areas", by providing some examples of the different ideas proposed during the negotiations.
\end{abstract}

\section{Keywords}

area-based management tools - marine protected areas - treaty negotiations - marine biological diversity - decision-making - conservation

There are today several organizations where States decide area-based management tools (ABMTs) and marine protected areas (MPAs). Some of these also have mandates in marine areas beyond national jurisdiction (IMO, OSPAR and CCAMLR for example). The cooperation within these organizations is operationalizing the obligation of States to cooperate to protect and preserve the marine environment found in several articles of the UN Convention on the Law of the Sea, including articles 192 and 197. However, the existing organizations are mostly limited in geographical scope (as OSPAR) or to a specific sector (as IMO). The sector can be as narrow as one marine animal or stock. Large oceans areas are not covered by any management organizations. This is 
the very reason for the intergovernmental conference - to bridge the gap between areas and measures to create a comprehensive and coherent system for the conservation and sustainable use of marine biodiversity in areas beyond national jurisdiction.

After two substantive sessions of the negotiations, the discussions on area based management tools, including marine protected areas, were well advanced compared to other parts of the negotiations. States had presented developed positions and proposals. However, a number of issues still needed clarification and definition for the negotiations to move forward.

However, some issues would need further consideration and work to move negotiations forward from this point. Two of the main issues that would need further discussions were:

First - what do we mean by area-based management tools (АВMTs) and marine protected areas (MPAs)? Second - how do we characterize the "global approach" vs the "regional approach"?

\section{1 \\ What Do We Mean by AвмT s and MPAs?}

Looking at existing treaties, there are some definitions of MPA and Авм T. The Convention on Biological Diversity (CBD) art 2 defines a Marine Protected Area as a "geographically defined marine area which is designated and regulated and managed to achieve specific conservation objectives". The CвD SBSSTA defined Авмт in 2018 as "a geographically defined area other than a Protected Area, which is governed and managed in ways that achieve positive and sustained long-term outcomes for the in situ conservation of biodiversity, with associated ecosystem functions and services and, where applicable, cultural, spiritual, socioeconomic, and other locally relevant values".

In the EU, an MPA is defined as an area with a higher level of protection for marine biodiversity than the surrounding areas. The EU-position in the negotiations has been based on this definition with some additions. For the negotiations the EU and its member states define an MPA as comprehensive management for a specific maritime area, whereas an Авм T is decided by a competent organisation for a specific sector or activity but without a specific management objective (a PSSA decided by IMO would be an example of an ABMT).

Also, national legislation contains different definitions.

The differences in definition and understanding may be a reason for some blockages in the negotiation. To overcome these blockages and move negotiations forward, there is a distinct need to reach a common understanding on what is what when talking about ABMT s and MPAs. 


\section{$2 \quad$ Global Approach vs Regional Approach}

At the second substantive session of the negotiations, there was already a convergence forming on several points. All positions presented aimed to create a system to guarantee enhanced and strengthened coherence and cooperation between existing actors and pointed to a need to fill the gaps in management.

Early during the negotiations negotiatiors talked about two distinct approaches, the global approach and the regional approach, and these were seemingly irreconcilable. However, with the advancement and increased detail of positions, this strict division no longer characterizes the status of negotiations.

However, by breaking down the positions it can be argued that, rather than placing position either in the "global" or the "regional" camp, positions sit on a sliding scale, or a spectrum, instead of a clear-cut regional or global division. A breakdown of some proposals presented during negotiations illustrates this:

1.

The agreement shall contain criteria for the designation of M PAs;

Proposal by states individually or collectively;

Consultations with all states, relevant organizations and civil society;

Scientific assessment; and

Decision by decision-making body. The decision is made on the basis of a management plan and States shall promote necessary measures in competent organizations

2.

The agreement shall contain criteria for the designation of MPAs;

Proposal by State or other actor;

Decision shall be made by a regional organization where existing;

Consultation before decision;

Scientific advice; and

Present to COP for discussion and comments.

3 .

Coherence by cooperation between States and organisations;

Consultation before designation;

Decision and implementation by regional organization where existing; and

Global body where no competent organization. 
By breaking down positions this way, one can identify several common elements: many positions contain the idea of identifying criteria; all include consultation before decision-making, and all include cooperation. The solution to a successful negotiation outcome would therefore be found in the proper balance between decision-making, coordination and cooperation. An agreement that is too heavy risks being too slow and too expensive. If the agreement is too general, there will still be no coherence in management, and it would be a long time until all ocean areas were covered by effective management structures.

Another central issue in the negotiations is the issue of "not undermining" existing organizations. This stems from the importance States place on existing organizations and their mandates to regulate and manage ocean areas. As mentioned in the beginning of this paper, large oceans areas are not covered by any management organization. The proposal has been made during the negotiations to include a provision in the Agreement to encourage the creation of regional organizations. The creation of such organisations would likely strengthen the ownership of marine management in ocean areas currently without regional management. For such organisations to succeed, capacity building is central. It is advisable therefore to consider making the creation and operation of regional organisations an objective for capacity building under the Agreement.

Finally, one must not forget the central role played by States as the actors within each relevant forum. Organizations cannot be effective and successful without the capacity and political will from the States that are their members. 
Lisa Eurén Höglund - 9789004422438

Downloaded from Brill.comఠ4/26/2023 09:51:33AM via free access 